\title{
O OURO CANIBAL: A TERRA VISTA PELA PERSPECTIVA CAPITALISTA E XAMÂNICA
}

\section{THE GOLD CANIBAL: THE EARTH VIEWED BY THE CAPITALIST AND XAMANIC PERSPECTIVE}

\begin{abstract}
ANGÉLICA FERREIRA ROSA
Doutorado em andamento na Universidade Federal do Paraná 2016 na área de concentração Relações Sociais, linha de pesquisa Novos Paradigmas do Direito e orientação do Doutor Elimar Szaniawski. Mestrado concluso na qualidade de bolsista na área dos Direitos de Personalidade, na linha de pesquisa Instrumentos de Efetivação dos Direitos da Personalidade pelo Centro Universitário de MaringáUnicesumar. Graduada pela Universidade Estadual de Maringá. Docente avaliadora de cursos de graduação em Direito do Ministério da Educação/INEP. Membro da Comissão OAB na escola de Maringá-PR. Membro da Comissão OAB de Justiça Restaurativa de Maringá-PR. Participa e organiza constantemente de eventos, congressos, palestras e simpósios e desenvolve projetos nas áreas Direito da Família, Direito Constitucional, Direito Civil e Direito Processual Civil, com ênfase nos Direitos de Personalidade. Foi advogada dativa da Comissão de ética da subseção de Maringá-Pr. Facilitadora em Justiça Restaurativa. Parecerista da Revista Jurídica da UFRGS. Membro do NÚCLEO DE ESTUDOS EM DIREITO CIVIL CONSTITUCIONAL? PROJETO DE PESQUISA VIRADA DE COPÉRNICO. Advogada. E-mail para contato: angelicaferreirarosa@hotmail.com.
\end{abstract}

\section{ELIAR SZANIAWSKI}

Doutor em Direito pela Universidade Federal do Paraná (1997). Mestre em Direito pela Universidade Federal do Paraná (1989). Professor Titular de Direito Civil do Setor de Ciências Jurídicas da Universidade Federal do Paraná. Professor e 
Pesquisador do Programa de Pós-graduação em Direito - Pós-doutorado, Doutorado e Mestrado, da UFPR. Conselheiro consultivo editorial - Revista Jurídica Mater Dei. Membro do Núcleo de Estudos em Direito Privado Contemporâneo. Membro do Núcleo de Pesquisas em Direitos Humanos da Universidade Federal do Paraná. Associado do Instituto dos Advogados do Paraná. Ex-professor da Escola da Magistratura do Estado do Paraná. Advogado particular - ADVOCACIA ELIMAR SZANIAWSKI. Atua principalmente nas áreas de Direito Civil, Responsabilidade Civil, Direito de Família, Direitos de Personalidade, Biodireito e Direito Animal.

\section{RESUMO}

Objetivo: O objetivo deste artigo é comprovar que a reserva indígena é indispensável para a preservação cultural, social e religiosa das tribos, pois está atrelada à proteção do habitat como garantia de seus costumes, credos e tradições, restando à Constituição de 1988 garantir o amparo às tribos indígenas com o uso dessas reservas.

Metodologia: $O$ estudo foi baseado em uma pesquisa bibliográfica e legislativa das Constituições de 1934 e 1988, bem como no posicionamento do Supremo Tribunal Federal, contido na Súmula no. 650.

Resultados: $O$ presente artigo demonstrou que os trabalhadores passaram a pressionar e manifestar-se para mudar o Estado brasileiro por intermédio de uma reforma agrária que gerou, em 1964, a edição do Estatuto da Terra. Assim como os movimentos pela terra, o Movimento dos Trabalhadores Rurais Sem Terra (MST) proporcionou indiretamente, em 1984, a positivação da "função social da propriedade" na Constituição de 1988, nas leis agrárias (como a Lei 8.629/1993) e nas matérias infraconstitucionais pertinentes à terra.

Contribuições: $O$ estudo contribuiu para demonstrar que o homem branco não consegue compreender a dimensão e a importância em manter-se as terras protegidas; constata-se que a observância do termo "uso tradicional" utilizado na Constituição de 1988 prejudica as comunidades indígenas, o que torna essa possibilidade de uso um direito não efetivo, permanecendo a discussão de como essas comunidades podem explorar as terras. Algumas autoridades defendem que esse uso é possível, mediante a assistência indispensável dos órgãos de fiscalização; no entanto, busca-se asseverar que legalmente é direito dos indígenas usar seu habitat, afirmando-se que é sua faculdade a exploração dessas terras, a título de função social da reserva indígena. 
PALAVRAS-CHAVE: Xamãs; homem branco; ouro canibal; reservas indígenas; proteção.

\begin{abstract}
Objective: To prove that the indigenous reserve is indispensable for the cultural, social and religious preservation of the tribes, as it is linked to the protection of the habitat as a guarantee of their customs, creeds and traditions, being an obligation of the Constitution of 1988 to guarantee the protection of indigenous tribes through the use of these reserves.
\end{abstract}

Methodology: The study was based on a bibliographic and legislative research of the Constitutions of 1934 and 1988, as well as on the position of the Supreme Court contained in Precedent no. 650.

Results: The present article demonstrated that the workers started to press and manifest themselves to change the Brazilian State through an agrarian reform that generated in 1964 the edition of the Earth Statute. Like the land movements, the Landless Rural Workers Movement (MST) indirectly provided in 1984 the enactment of the "social function of property" in the Constitution of 1988, the agrarian laws (such as Law No. 8,629/1993) and relevant non-constitutional matters relating to land.

Contributions: The study has shown that the white man cannot understand the scale and importance of maintaining protected lands; the observance of the term "traditional use" used in the Constitution of 1988 is detrimental to indigenous communities, which makes this possibility of using an ineffective right, and there remains a discussion of how these communities can exploit land. Some authorities argue that such use is possible through the indispensable assistance of the supervisory bodies; however, it seeks to assert that it is legally the right of indigenous people to use their habitat, stating that it is their faculty to exploit these lands as a social function of the indigenous reserve.

KEYWORDS: Shamans; white man; cannibal gold; indigenous reserves; protection.

\title{
INTRODUÇÃO
}

Pode-se afirmar sem incorrer no risco de exagerar que não existe nada de mais antagônico do que a visão dos Xamãs em relação às terras, principalmente 
comparado com o entendimento dos europeus que sedentos por descobertas fantásticas que lhe mudassem completamente o status social, consequentemente fizeram das grandes navegações não simplesmente um momento importante de descobertas, contatos com outras culturas e aprendizado, mas sim de explorações e dominações, a primeira em virtude da extração do que fosse considerado vantajoso monetariamente, em segundo, por meio da cultura e da religião impunham a vestimenta, o comportamento, dentre outros, e o culto religioso, o Cristianismo por meio das missões como meio de garantir o controle total daqueles que eram considerados inferiores, ou seja, Ihes tolheram o direito de escolha para que conhecendo a religião imposta pudessem participar ou não, a exclusão dessas pessoas que insurgiam era motivo para legitimar o uso da força estatal contra o indivíduo, disso decorreria o uso da violência física e psicológica, assim como, a perda de suas terras e tantas outras situações.

No Brasil, a Lei de Terra de 1850 trouxe a posse como forma de aquisição da terra, desde que houvesse o registro (legalização) e estabeleceu as terras devolutas para a colonização dos indígenas, os indígenas civilizados, os considerados convertidos, índios que resistissem não teriam suas terras protegidas, somente com a Constituição Federal de 1934 que as terras indígenas não mais foram consideradas expressamente como devolutas, mesmo com a Constituição Federal de 1988 continuou positivando que as terras indígenas são do domínio do governo entendimento que remonta desde o Império onde nunca se considerava o índio como capacitado, mas, por exemplo, por força da Constituição de 1988 o Supremo Tribunal Federal editou a Súmula 650 onde os aldeamentos indígenas abandonados deixaram de serem bens da União.

A distinção jurídica entre propriedade e posse que dentre outros fatores significa o domínio sobre a terra mesmo que a distância, também possibilitou que o valor de uso da terra fosse substituído por um valor de troca, como se entende da possibilidade de disposição dessas terras, assim, com a Constituição Federal de 1988 se positivou a função social à posse, pois a considerou como instrumento de conscientização do dever constitucional de observar e proteger a propriedade, 
conectando posse com propriedade e discriminando sanções para aqueles que descumprirem-na, como consta no art. 184 do mesmo diploma.

A Constituição Federal de 1988 atribuiu aos indígenas o titulo de "senhores da terra", vinculando a proteção indigenista a terra, o que é de suma relevância, já que a terra é elemento primordial para preservação cultural, social e religiosa das tribos, a proteção da cultura indigenista necessariamente está atrelada a proteção do habitat de determinada tribo, a área de preservação que preserva o habitat do povo que a habita, a vegetação e todo ciclo de vida presente nesta determinada área pela utilização tradicional dos povos indígenas, para a preservação e garantia de seus costumes, credos e tradições, mas ainda há divergências se isso é de fato garantido, dessa forma, o presente trabalho tem como objetivo discorrer em especial sobre a visão histórica da cultura Xamânica do que a terra representa diferenciandoa da visão europeia, para que se possa comprovar a indispensabilidade de garantir as reservas indígenas como garantia e manutenção da perpetuação da cultura indígena.

\section{O DIABO E A TERRA DE SANTA CRUZ: A VISÃO EUROPEIA DOS INDÍGENAS E DAS TERRAS BRASILEIRAS}

A obra "O Diabo e a Terra de Santa Cruz" de autoria de Laura de Mello e Souza trouxe um panorama histórico e com aprofundamento teórico, fruto de suas pesquisas de doutorado, sobretudo em Portugal e no Brasil que cujo título do livro já evidencia o antagonismo das visões europeias em relação às terras brasileiras e dos e então habitantes, os indígenas.

O Brasil foi simultaneamente considerado paraíso e inferno, sendo o nome de Santa Cruz dado por Pedro Álvares Cabral quando do descobrimento das terras brasileiras. Mas pode ser que o Frei Vicente Salvador tenha designado o nome Brasil pela presença da madeira de cor avermelhada, em que ele deu uma 
explicação complicadíssima e religiosa do embate entre o bem e o mal (SOUZA, 1986).

O céu (o reino de Deus) e o inferno (o reino do demônio), ou seja, a colônia poderia ser vista por meio de duas óticas, como domínio de Deus (paraíso) ou do Diabo (inferno), essa ambiguidade é característica do Renascimento considerado por alguns autores como enigmático e contraditório. O Diabo é relacionado ao clima da terra, das condições dos animais selvagens, peçonhentos há relato de padres, os quais afirmavam que as pulgas eram as perdições das ceroulas e camisas dos padres, como também decorriam do fato dos indígenas urinarem em qualquer lugar e do número elevado de bichos que viviam soltos na natureza (Ibidem).

Nesse período ocorria grande a influência da Contra Reforma, principalmente entre os jesuítas, tendo em vista o papel do Concílio de Trento para a universalização e expansão da Igreja e da fé, como frente aos ideais impregnados por Lutero. Os protestantes defendiam a ideia do bom selvagem, para os jesuítas o índios como bárbaros, preguiçosos, ou seja, eles eram considerados relacionados aos seus maus costumes (MAGALHÃES, 2000, p. 77), como seres perigosos, devido aos seus rituais antrofágicos (AGNOLIN, 2002), os índios acreditavam que ao comer o guerreiro da outra tribo eles estariam incorporando o espírito dele.

A representação da tela do Homem Tapuia que se encontra no museu de Copenhague que data do período de 1641 por Albert Eckhout, demonstra pela pintura o homem selvagem, um homem que está nu, com armas de guerreiros em suas mãos, com o que parecem ser sandálias aos pés, com adorno peniano que simboliza a passagem da infância para a maturidade, a paisagem envolta remete a ideia de como era a natureza, a selvageria do ambiente pode ser observada nos pés do índio onde se encontra uma cobra morta (CHICANGANA-BAYONA, 2008).

Há também a figura da Mulher Tapuia que também se encontra no mesmo local e pintada pelo pintor ora já citado acima, interessante frisar que é a representação por um Holandês dos índios que habitavam o Brasil naquele determinado período. Ela é representada nua tendo cobertas suas partes íntimas na parte da frente e de trás por folhas com o que parecem ser sandálias, essa agora 
até mesmo representada com pulseira. O que mais chama a atenção é o fato dela segurar na mão direita uma outra mão humana com parte de um braço e nos cestos que ela tem nas costas tem uma perna humana decepada, a natureza composta por plantas nativas, a índia se equilibra em pedras num riacho límpido, onde um cachorro bebe a água, entre as pernas da índia se observa outros índios que parecem estar guerreando ao fundo (Ibidem).

A pintura da Mulher Tupi que também se encontra no mesmo museu e fora pintada pelo mesmo pintor na data de 1641 é bem diferente. Nela se observa até mesmo a presença de uma saia, mesmo que os peitos ainda estejam nus, no braço direito ela segura o filho na cabeça segura um cesto de palha cheio de objetos artesanais junto a uma bananeira que foi uma planta trazida pelos Europeus e, no fundo da tela é observável uma fazenda canavieira com pessoas trabalhando. $O$ Homem Tupi continua com o peito nu só que vestido com um calção de pano, em que aparece uma faca, ele segura flechas e lanças com as mãos, no chão da tela aparece uma mandioca cortada ao meio, no final da tela aparecem índios num rio, o que dá a alusão de estarem lavando roupas e também os próprios corpos (SANTOS JúNIOR, 2006).

Em se tratando de homens selvagens, no Renascimento, vigorou uma atitude de ambivalência de medo e inveja, as quais ameaçavam a sociedade, mas eram exuberantes, sexualmente ativos de existência livre e seus atributos espirituais tidos como negativos, enquanto os dotes físicos positivos. Os indígenas atolavamse mais e mais no engano e na idolatria, adoravam o diabo através de seus ministros, os Pajés. Eles eram induzidos pelo maligno, por isso, incapazes de discernimentos por serem privados de razão (SOUZA, 1986).

Os indígenas eram de difícil submissão em relação ao regime escravocrata e eclesiástico, já que eles aparentemente adoravam a cruz, mas não deixavam seus ritos e cultura, quando os mesmo estavam inseridos nesse regime até levantes poderiam acontecer, massacres. Deste modo, para os colonos proprietários de terras seria interessante aceitar as práticas indígenas contrárias aos dogmas religiosos impostos pelo poder eclesiástico para que dentro de suas terras tivessem 
o maior controle dos rituais, isso inclui a participação pessoal do próprio proprietário de terras nessas celebrações com a finalidade de controlá-los socialmente e ideologicamente (lbidem).

Os jesuítas tentavam catequizar e civilizar os índios, evidentemente que essas práticas eram de acordo com o próprio referencial europeu em consonância com as próprias explicações dadas pelos nativos dos elementos que os cercavam, numa terra que as pessoas não possuíam muita moralidade que necessitavam de orações, na qual até mesmo a falta de chuvas estava relacionada ao excesso de pecados cometidos pelos seus habitantes (PINHO, 2006, p. 124-125).

O Brasil passou a ser o prolongamento da metrópole, a América era muito mais filha da Europa do que a África da Ásia, evidentemente que ressalvadas as suas peculiaridades, como as geográficas. A expansão do ocidente ficou caracterizada pela bifrontalidade, já que por um lado se incorporava novas terras sujeitando-as ao poder das monarquias europeias. Pelo outro ganhava-se novos fiéis pela propagação da fé católica, afinal, os eclesiásticos entendiam que o seu descobrimento fora ação divina, ou seja, Deus escolheu os portugueses que por isso tinham o dever de produzir nas terras riquezas materiais por meio da exploração da natureza e também resgatando as almas para o divino, mas havia religiosidade nessas terras não era tudo "largado" isso se deu principalmente por força dos jesuítas que muito trabalharam e adentraram em regiões longínquas brasileiras. (SOUZA, 1986).

Toda essa diversidade pode-se ser observada hodiernamente pela compreensão da diversidade cultural e étnica que distância diversos grupos tribais entre si é de fundamental importância, já que segundo o senso de 2010 do IBGE (Instituto Brasileiro Geografia e Estatística) à época no Brasil, existiam cerca de 817.963 mil índios, distribuídos entre 220 povos, compondo cerca de $0,4 \%$ da população nacional, onde 82 grupos tribais ainda não foram catalogadas pelo órgão de assistência ao índio (RESENDE, 2014).

Como se pode analisar dos dados do IBGE, não está devidamente catalogado esses números, o que dificulta a proteção da FUNAI (Fundação Nacional 
do Índio) que tem a missão de Coordenar o processo de formulação e implementação da política indigenista do Estado brasileiro, instituindo mecanismos efetivos de controle social e de gestão participativa, visando à proteção e promoção dos direitos dos povos indígenas. Ainda que pela primeira vez na história jurídica brasileira a Constituição Federal de 1988 tenha trazido um capítulo inteiro à proteção do índio, e nele tendo protegido especificamente as tradições, línguas, culturas, ou seja, a sua qualidade indígena, diferentemente do que vimos no texto cujas tentativas de transformá-los em civilizados aptos ao trabalho e à sua religiosidade eram uma constante. Evidente que isso não significa afirmar que na realidade deixou-se de vê-los de forma preconceituosa e discriminatória, historicamente no Brasil eles foram vítimas de enormes atrocidades e massacres (Ibidem).

Nessa diapasão, cumpre salientar que todos os poderes precisam se posicionar em prol de garantir o tratamento digno aos índios, tanto na elaboração legislativa, quanto na execução e fiscalização dessas leis. Eles também possuem pouca representatividade na criação de políticas públicas e, a eficiência da proteção constitucional em relação às reservas indígenas é questionável, pois até mesmo o entendimento e a importância da terra para o índio é totalmente diferente daquele que o homem branco possui, desse modo, cumpre retratar essa visão e enfatizar a função social que a terra precisa necessariamente cumprir.

\section{A PROPRIEDADE PRIVADA E SUA FUNÇÃO SOCIAL EM TERRAS BRASILIS}

Antes mesmo de tratarmos o assunto é importante conceituar o que é propriedade e como ela se desenvolve está relacionada com a transição do homem selvagem para o homem sedentário (ASSIS, 2008, p.782), em relação aos espaços físicos observa-se que o sedentarismo é resultado doa conduta do homem que retira da terra o seu sustento e também os seus valores, pois aquele que fosse detentor da propriedade, ainda mais notável nos primórdios da civilização que o chefe de 
família, o pater famílias no Direito Romano, correspondia ao poder soberano de ser o responsável por todas as decisões que envolvessem a família, incluindo o fogo sagrado que remetia aos deuses aos quais todos deveriam seguir os membros familiares (COULANGES, 2006).

O conceito de direito de propriedade sempre fora considerado como absoluto, indisponível, quase uma garantia fundamental do indivíduo (GROSSI, 1992, p. 31-32 APUD, ASSIS, 2008, 782).

No Brasil, o direito foi formado por meio do direito português, mesmo no período colonial, nas Ordenações portuguesas (Afonsinas, Manuelinas e Filipinas), em que a primeira Constituição brasileira, de 1824, deu início à ordem jurídica nacional e independente de Portugal, no período imperial, as Ordenações tiveram vigência no Brasil até o Código Civil, em 1916, nesse período colonial a propriedade da terra era de povoamento da terra e exploração dos recursos naturais, as terras que eram de Portugal, mas concedidas aos particulares num sistema chamado de sesmarias, em que essas terras estavam associadas e condicionadas ao cultivo para abastecer a agricultura europeia (ALVES; MATIAS, 2015, p. 357).

Pela Constituição de 1824 garantiu os direitos civis e políticos, como a liberdade, a segurança individual e a propriedade, para protegê-la o Estado poderia indenizar o cidadão se por meio desse interesse público precisasse da propriedade (Ibidem), a Lei de Terra de 1850 trouxe a posse como forma de aquisição da terra, desde que houvesse o registro (legalização) e também estabeleceu que as terras devolutas para a colonização dos indígenas, alguns pontos sucintos da Lei (PODELESKI, 2009, p. 51-52):

Fixou-se a proibição de terras devolutas por qualquer outro título que não fosse de compra, aplicando-se punição de multa para os que se apossassem de terras devolutas ou de alheios. As terras devolutas passaram, então, a serem aquelas que não estariam aplicadas a algum uso público nacional, provincial ou municipal. As que não tinham título que as legitimasse pelas condições de medição, confirmação e cultura e aquelas que não se achavam ocupadas por posses foram legitimadas por esta Lei. As terras que tivessem posse mansa e pacífica, achando-se cultivadas ou com princípio de cultura e moradia seriam legitimadas. O princípio de cultura não era considerado para os simples roçados, derrubadas ou queima de matos era necessária a comprovação da permanência. $O$ 


\begin{abstract}
Governo determinaria o prazo para a "legalização" das terras, podendo as províncias prorrogá-lo. A terra não medida no prazo perderia seu título de posse e o possuidor ficaria sem a posse de toda a terra inculta que antes estava sobre seu poder. O governo reservaria parte das terras devolutas para colonização dos indígenas, para fundações de povoações, abertura de estradas, construção naval e outras que julgasse necessário. As vendidas estariam sempre sujeitas a ônus, se nelas fossem encontradas; a venda, preferencialmente para os possuidores de terra com cultura e criação, contanto que tivessem meio de aproveitá-las. O governo, a custa do Tesouro, ficara autorizado a mandar vir, anualmente, certo número de colonos livres, para serem empregados em estabelecimentos agrícolas ou na Administração Pública. O governo deveria criar a Repartição Geral de Terras Públicas, que seria encarregada de toda a legalização da terra devoluta, podendo aplicar prisão de até três meses e multas nos Regulamentos da presente Lei. E, por fim, anulava todas as disposições em contrário à Lei.
\end{abstract}

Evidentemente que essa proteção se referia aos indígenas considerados civilizados, os convertidos, índios que resistissem não teriam suas terras protegidas, o que demonstrava que essa proteção não era dispensada a todos, já que os índios que resistissem não teriam suas terras garantidas (MARCHINI, 2011, p. 89), mas foi somente com a Constituição Federal de 1934 que as terras indígenas não mais foram consideradas expressamente como devolutas, mesmo com a Constituição Federal de 1988 continuou positivando que as terras indígenas são do domínio do governo entendimento que remonta desde o Império onde nunca se considerava o índio como capacitado (Ibidem), ressaltando que no século XIX, a propriedade latifundiária era a principal riqueza, pois poucos a detinham e o direito de propriedade absoluto e transmitido por herança (ALVES; MATIAS, 2015, p. 357).

Foi somente após a Constituição Federal de 1988 que o Supremo Tribunal Federal editou a Súmula 650 onde os aldeamentos indígenas abandonados deixaram de ser bens da União, mesmo antes dela o STF havia decidido que a competência para legislar sobre as terras indígenas abandonadas era da União, antes a proteção geral para as terras indígenas, afinal, os índios poderiam ser expulsos das próprias terras, os aldeamentos indígenas anteriormente se eles fossem abandonados caberiam o adquirir por agentes privados, mas com ela todas as terras indígenas passaram a ser protegidas por outras pessoas apenas os 
aldeamentos abandonados extintos é que deixam de contar com a proteção constitucional (Ibidem).

A ideia de função social da propriedade pode ser vista na doutrina cristã na Idade Média, mas somente no final do século XIX que se consagrou nas Constituições modernas, a ideia de propriedade foi relacionada a um dever em que a coletividade na Encíclica Quadragésimo Anno, em que ao legislador restou a disciplina do exercício do direito de propriedade (CHALHUB, 2003, p. 305).

Pode-se afirmar que no século XIX devidas às alterações de concepções em relação às modificações da propriedade individualista, o que fez de forma substancial a preponderância o exercício da propriedade como função social, a utilidade social dela para que os bens ainda que responsáveis pela produção da riqueza possam também responder aos anseios e necessidades do coletivo, a partir da revolução industrial, pela qual o proprietário passou a ter como objeto a ação, que corresponde a uma fração do capital, e não mais os bens que constituem o capital; a ideia de propriedade passa da posse para o crédito, ademais a utilização do solo é sem sombra de dúvidas merecedoras de tutela (Ibidem).

No século XIX os vários movimentos contestam o capitalismo, os proletários visam por meio da luta à emancipação e o final da Primeira Guerra Mundial é marcado por esse contexto, assim como, os camponeses, por meio de todos esses ditames o estabelecimento de concessões e reformas para manter o modo de produção, como se deu na Europa (CALMON; PINTO, 2010, p. 112-113).

No Brasil, não fora diferente, os trabalhadores passaram a pressionar e se manifestar para mudar a conjuntura do país, como é entendido do sufocamento dos movimentos de reforma agrária que gerou em 1964 a edição do Estatuto da Terra, como já analisado acima, como um avanço, com o final da ditadura militar ressurgem os movimentos pela terra como o Movimento dos Trabalhadores Rurais Sem Terra (MST), em 1984 e o estabelecimento positivado da "função social da propriedade" na Constituição Federal de 1988, que remonta até mesmo outra conceituação jurídica de propriedade contribuindo para a propriedade rural e para a reforma 
agrária, o Direito Agrário, com o Estatuto da Terra, as leis agrárias (como a Lei 8.629/93) e as matérias infraconstitucionais pertinentes a terra (Ibidem).

\section{O OURO CANIBAL: A TERRA VISTA PELA PERSPECTIVA CAPITALISTA E XAMÂNICA}

A cultura dos Xamãs entende o ouro como metal precioso de uma forma diferente: o ouro tem uma conotação espiritual com a terra. A visão indígena é explicada pela cultura dos mesmos, que foram inseridos como mão de obra na Amazônia por intermédio de um dos ciclos baseados na exportação de produtos extrativos de drogas nos séculos XVII, cacau no século XVIII ou borracha no século XIX (ALBERT, 1995, p.2).

É importante situar que depois do colapso ocorrido com a borracha em 1910, a economia foi sustentada por frentes extrativistas, garimpeiras e pecuaristas, até o advento dos planos de geopolítica dos militares de 1960 e 1970. A partir desse momento houve uma política de grande escala para a ocupação demográfica de desenvolvimento econômico e de redistribuição espacial promovida pelo Estado. Esta situação ocasionou um intenso movimento de competição territorial centrada no controle de recursos naturais e dos espaços produtivos, o que infelizmente acabou por mais uma vez impactar os índios (Ibidem).

Tais movimentos descritos acima geraram certos movimentos de resistência baseados nas reivindicações de reservas de terras, os chamados contra espaços diferenciados no interior da fronteira, as terras indígenas, as reservas extrativistas. Para isto surge um discurso ideológico que visa proteger a identidade social e política desses grupos frente aos interesses econômicos sobre suas terras, em que as igrejas, as ONGs e as organizações não governamentais representam lutas na mídia mundial para a autoafirmação étnica dos indígenas (Ibidem).

Foi depois da Segunda Guerra Mundial que houve mudanças significativas em relação a preocupação para com os indivíduos e grupos e a proteção de seus 
direitos legais e humanos. Deste modo, pode-se afirmar que passou a ser levado em consideração nacional e internacional o devido tratamento aos povos indígenas, isso quer dizer que a comunidade internacional tem os aparatos que podem pressionálos e limitá-los para o reconhecimento dos direitos e das liberdades como fundamentais (SALGADO; GOMIZ, 2010, p.28-29). Os exemplos dessas conquistas:

\begin{abstract}
A Declaração Americana de Direitos e Deveres do Homem, a Declaração Universal dos Direitos Humanos, a Convenção sobre Prevenção e Punição do Crime de Genocídio, a Convenção União Europeia para a Proteção dos Direitos do Homem e das Liberdades Fundamentais, a Carta Social Europeia, o Pacto Internacional sobre os Direitos Civis e Políticos, o Pacto Internacional de Direitos Econômicos, Sociais e Culturais, a Convenção Americana sobre Direitos Humanos, a Convenção Internacional sobre a Eliminação de todas as Formas de Discriminação Racial - induzidas no vinte anos depois de 1948 - estabeleceram as bases para um sistema jurídico internacional dos direitos humanos que seria estendido nas décadas seguintes, dando espaço para órgãos e tribunais internacionais com jurisdição sobre os estados, para receber reclamações de indivíduos e grupos afetados pela violação de seus direitos fundamentais (Ibidem).
\end{abstract}

Isso influenciou uma nova representação indígena que desenvolve uma simbolização política complexa e original que se relaciona à especificidade cultural de cada grupo indígena. Ressalta-se que dentro de cada comunidade que eles representam existem determinadas especificidades divergentes na maneira de analisar as situações de contatos e reagir a elas.

Há intertextualidade cultural do contato por intermédio da etnopolítica (discurso que o homem branco constrói em relação aos índios), em que a autodefinição de cada protagonista é somente dessa representação e da autorepresentação dos atores interétnicos em relação à imagem que eles possuem do outro e da sua própria espelhada no outro. As categorias brancas são as de autoobjetivação que ocorrem por intermédio das categorias brancas da etnificação e reelaboração cosmológica dos efeitos do contato, o discurso étnico se legítima pelas referências ao saber cosmológico, o qual se reconstrói a partir daquele (ALBERT, 2015, p.4).

Os Yanomamis quando analisam o contato interétnico visualizam os brancos como seres sub-humanos, periféricos, ininteligíveis. Sua população ao redor de mais 
de sete mil vivem no território Brasileiro e ocupando a parte ocidental do Estado de Roraima. Tendo esta região sido sustentada por verbas federais de 1965 a 1985, ficou estagnada a uma fronteira de povoamento com objetivos geopolíticos, desprovida de bases econômicas, tornou-se favorável, até certo período a essa população, mas que em 1986 a fronteira do ouro acabou explodindo, acarretando entre outros fatos em 1987, o assassinato de quatro líderes indígenas por garimpeiros que estavam os impedindo 0 acesso às jazidas de ouro da região (ALBERT, 2015, p.6).

O impacto em relação ao território Yanomami é imaginável, pois Roraima apresentou de trinta a quarenta mil garimpeiros explorando cerca de cento e cinquenta garimpos servidos por oitenta e duas pistas de pouso clandestinas, o que certamente ocasionou um impacto epidemiológico e ecológico trágico para os Yanomami. Além dos danos às terras tais como o desmatamento, a poluição da rede hidrográfica e a caça desenfreada acarretando violência e doenças, como exemplo, a malária, a gripe, o sarampo, a coqueluche, a hepatite, a tuberculose, dentre outras (Ibidem).

A empresa Irlandesa Celestial Ventures GreenPLC celebrou um contrato de 30 anos para exploração com a Organização do povo Munduruku, em relação ao território Munduruku no município de Jacareangá no Pará, que está registrado sob o número 473531-11-PVO1, com área total de 2.381.795,7765 ha (dois milhões trezentos e oitenta e um mil hectares setenta e sete ares e sessenta e cinco centiares) em que ambas concordam:

Parágrafo 1, 1.1 Celestial Green Ventures PLC concorda em pagar o valor total e Maximo de USD 120.000.000,00 (cento e vinte milhões de US Dólares), a Associação Indígena Pusuru-AIP, Estado do Pará, Brasil, por esta concordar e cumprir todos os termos e condições do contrato número 473531-11PV01 e Anexo 1. 1.2 O pagamento previsto no parágrafo 1.1 transfere para a empresa os direitos de todos e quaisquer créditos de carbono obtidos com quaisquer metodologias e sobre os direitos de todos e quaisquer certificados ou benefícios que venha a obter com a biodiversidade nas áreas do contrato. Parágrafo 2, 2.1 Os pagamentos serão efetuados em 30 (trinta) parcelas de igual valor de USD 4.000.000,00 (quatro milhões de US dólares), pagas anualmente de 2012 a 2041, até ao dia 31 de Dezembro de cada ano e corresponde ao acordo número 47353111-PV01 e Anexo 1 assinado, reconhecido em notário e registado em 


\begin{abstract}
cartório. Parágrafo 33.1 Celestial Green Ventures PLC confirma que efetuará a totalidade dos pagamentos no prazo de 30 anos a partir de 2012 conforme referido no ponto 2.1, deste anexo. Parágrafo 44.1 Celestial Green Ventures PLC não aceita qualquer responsabilidade por eventuais custos a pagar pelas Associação Indígena Pusuru-AIP, como resultado dos valores recebidos ao abrigo deste contrato. Parágrafo 55.1 Celestial Green ventures PLC, não se responsabiliza por quaisquer impostos incorridos pela Associação Indígena Pusuru-AIP, como resultado deste contrato. Parágrafo 6 6.1 A Associação Indígena Pusuru-AIP concorda com os valores referidos no parágrafo 1.1 e comprometem-se a cumprir todas as condições do contrato número 473531-11-PV01 e Anexo 1.
\end{abstract}

No ano de 2015 como se pode observar da leitura ipsis litteris do contrato, não houve a venda somente dos créditos de carbono, bem como, de quaisquer direitos de todos e quaisquer certificados ou benefícios que viessem a obter com a biodiversidade nas áreas do contrato, ou seja, ocorre a venda de todos os benefícios e garantem todos os direitos em relação à exploração dessas terras, desse modo, interesses podem estar subentendidos nessas vendas de crédito de carbono, em que o pagamento feito no prazo de 30 anos, o que também se torna incabível, haja vista a própria exploração dessas terras o que por si só já seria mais que suficiente em um curto prazo de tempo para que ocorresse o pagamento.

Ainda, a empresa não aceita qualquer responsabilidade por eventuais custos a pagar pela Associação Indígena Pusuru-AIP, como resultado dos valores recebidos ao abrigo deste contrato, nem se responsabiliza por quaisquer impostos incorridos pela Associação Indígena Pusuru-AIP, como resultado do contrato, ou seja, esse contrato é flagrantemente lesivo aos indígenas, ressalvando que os interesses por essas terras são amplos, pois a biodiversidade é relevante, também a possibilidade de garimpagem desses territórios.

Os garimpeiros comem a terra da floresta por causa do ouro, a destruição da floresta ocasiona as febres, as doenças mortais como visto há nisto tudo explicação mitológica, em que o ouro escondido no interior da terra tem uma simbologia, a cultura Xamânica entende que são os seus espíritos que protegem a floresta. $O$ ouro é matéria quente e perigosa, um anti-alimento para eles, por isso, foi escondido embaixo da terra, a fim de proteger os humanos de suas propriedades patogênicas (ALBERT, 2015, p.10). 
As propriedades patogênicas estão associadas ao pensamento Yanomami sobre os efeitos epidemiológicos do contato. $O$ processo em que queimam o ouro e o expõem ao sol, mataria o ouro, já a fumaça que se espalharia em todas as direções acabaria afetando os seres humanos e a floresta, a fumaça patogênica tem dois aspectos, o visível aos olhos dos brancos e o da caça canibal do "espírito da epidemia", observável somente aos auxiliares dos Xamãs, por isso, a alusão da figura dos brancos como espíritos canibais, onipresente na Amazônia (lbidem).

O único meio de evitar a queda do céu é continuar com o trabalho xamânico evitando que a corrida do ouro destrua a floresta, em escala global, o mundo, desse modo, afirma-se que para os Xamãs existe o significado espiritual que impede essa exploração. Porém, não para o homem branco aqui representado pelas grandes corporações em que até mesmo se questiona as consequências do Decreto $\mathrm{n}$. 4.887, de 20 de novembro de 2003 que "Regulamenta o procedimento para identificação, reconhecimento, delimitação, demarcação e titulação das terras ocupadas por remanescentes das comunidades dos quilombos de que trata o art. 68 do Ato das Disposições Constitucionais Transitórias".

Para Maréas (2015) O Decreto $\mathrm{n} . .4 .887 / 03$ estabelece os procedimentos administrativos que se identifique, reconheça, delimite, demarque a titulação da propriedade definitiva dessas terras, as quais são remanescentes das comunidades quilombola de acordo com 0 art. 68 do Ato das Disposições Constitucionais Transitórias, identificando esses territórios, definindo o procedimento administrativo, onde caberá a competência ao INCRA, em que a União Federal e os Estados Federados poderão regularizá-los (SOUZA FILHO, 2015, p. 81).

Importa salientar que mesmo tratando-se de uma conquista sem precedentes para os povos indígenas e por isso, em vários aspectos, sua constitucionalidade foi debatida para que eles não tivessem a possibilidade de possuírem todos os direitos de serem proprietários dessas terras e, nem que tivessem a posse delas. Contudo, a Constituição Federal de 1988, em seu art. 226, $\S 5^{\circ}$ declara tombados os remanescentes de comunidades quilombolas, em que o artigo protege o conceito de patrimônio cultural, ou seja, os quilombos são parte 
desse patrimônio cultural, em que o art. 68 do ADCT, entende que: "Aos remanescentes das comunidades dos quilombos que estejam ocupando suas terras é reconhecida à propriedade definitiva, devendo o Estado emitir-lhes os títulos respectivos". Portanto é efetivo o reconhecimento dessas comunidades, mesmo assim, os dados que se tem na atualidade como os trazidos pela Fundação Palmares de que até 2013 havia fornecido 2.007 certificações de existência de comunidades quilombolas, também a Confederação Nacional das Comunidades Quilombolas (CONAQ) trouxe que de 3.000 comunidades espalhadas por pelo menos 24 Estados brasileiros (SOUZA FILHO, 2015, p. 79-80).

O Supremo Tribunal Federal decidiu que "os direitos dos índios sobre as terras que tradicionalmente ocupam foram constitucionalmente 'reconhecidos', e não simplesmente outorgados, com o que o ato de demarcação se orna de natureza declaratória, e não propriamente constitutiva. Ato declaratório de uma situação jurídica ativa preexistente" (SILVA, 2016, p. 2). (Ementa da Pet. 3.388/RR - Raposa Serra do Sol, item 12, trecho).

Os que teriam interesses em que os direitos dos povos às terras indígenas não fossem constitucionalmente 'reconhecidos', são as grandes corporações que visam, na maioria das vezes, explorar esses territórios, em que há o regime de "exceção privado das corporações para montar programas eficazes de responsabilidade social, neutralizar a crítica a seus projetos e viabilizar o controle sobre o território" (ACSERALD; BARROS, PINTO, 2015, p.117), em que segundo os doutrinadores:

\begin{abstract}
As técnicas de controle territorial, desenvolvidas durante a ditadura, e o repertório de ações destinadas a obter um controle análogo por parte de empresas em grandes projetos de investimento que o autoritarismo se reproduz e a democracia se vê corroída pela base. (ACSERALD; BARROS, PINTO, 2015, p.117).
\end{abstract}

Uma vez que não é condizente com a democracia, pois impede o acesso da população em relação aos movimentos que problematizam os impactos que esses grandes projetos dessas corporações ocasionam na sociedade e no ambiente. Por 
sua vez, para essas corporações esses ambientes não passam de uma Natureza marginalizada, já que são reservas ou resíduos da exploração dos seus recursos, também condenada e sem conformidade entre as "áreas verdes" e as outras áreas de conservação/proteção.

O Brasil, a União Europeia e os Estados Unidos, inseriram-se no estudo e na proteção em temas associados à cultura e aos fatores ambientais, trata-se de interpretações e posições em relação à biodiversidade e aos conflitos socioambientais, como a Convenção sobre Diversidade Biológica (CDB) promulgada na Rio-92, e da Declaração Universal sobre a Diversidade Cultural estruturada pela UNESCO, de acordo com as Nações Unidas (ONU) (ALMEIDA, 2015, p.41).

A biodiversidade pode ser compreendida diretamente relacionada com a sociodiversidade, pelo surgimento dos novos "sujeitos sociais", eles que "se apropriam dos recursos naturais consoante uma autoconsciência cultural acentuada" (Ibidem, p. 42). Esses sujeitos constroem identidades coletivas próprias, como os significados de "etnia", de "tradicional" e demais fatores identitários, os quais estão diretamente ligados "a preservação ambiental articulada com rituais de passagem, que hierarquizam o tempo e os espaços físicos, delineando uma ação cultural profunda" (Ibidem), por isso, tanto as florestas amazônicas quanto a atlântica, dentre outras, são partes inseparáveis dos seus povos, como o são os indígenas que tradicionalmente ocuparam essas terras e fazem uso sustentável delas.

Um caso bem importante que se pode citar nesse contexto é o da posição do Estado do Suriname que negou o reconhecimento identitário aos direitos coletivos do povo Saramaka, o que representou o descumprimento intencional do conteúdo material e procedimental disposto na Sentença, mantendo práticas coloniais violadoras, de valores etnocêntricos e também racistas que violam a percepção do "outro", "pois o compreende apenas como opositor à soberania política estatal, ao desenvolvimento socioeconômico capitalista e à manutenção do status quo jurídico nacional" (OLIVEIRA, 2012, p. 47-48).

Pode-se afirmar que o Estado do Suriname foi forçado ao reconhecimento dos direitos coletivos à propriedade, a personalidade jurídica e principalmente a 
identidade, tratando adequadamente a diversidade cultural, a cidadania e a soberania, para a inclusão social do povo Saramaka mesmo que isso gere certa dificuldade em relação à adequação dos conceitos jurídicos nacionais (Ibidem).

Para os Xamãs há a fetichização da Natureza enquanto exterioridade selvagem do mercado e da sociedade. O discurso ecologista passou a ser uma simbolização intercultural adequada à expressão e à validação de uma visão do mundo e de um projeto político Yanomami nacional e internacionalmente. Assim, o discurso ambientalista das ONGs são relevantes para construir a história indígena, porém não trazem muitas soluções (ALBERT, 2015, p. 21).

A "Ecologia" seria o poder dos espíritos no controle das forças entrópicas dos cosmos, em que a ecologia científica com os ecossistemas não-antrópicos (como reservas naturais de recursos), nem a ecologia política e a sua estratégia de conservação da biodiversidade (como protótipo pós-moderno da "boa" mercadoria), respondem aos anseios indígenas (Ibidem).

As comunidades quilombolas sempre sobreviveram invisivelmente, e infelizmente essa realidade ainda não mudou. Segundo o senso de 2010 do IBGE (Instituto Brasileiro Geografia e Estatística) existiam cerca 817.963 mil índios, distribuídos entre 220 povos, compondo cerca de $0,4 \%$ da população nacional, onde 82 grupos tribais ainda não haviam sido catalogados pelo órgão de assistência ao índio, o que dificulta tanto o reconhecimento quanto proteção deles pela Fundação Nacional do índio-FUNAI. Observa-se que devido a isso, a legalidade em se garantir esses direitos sobre as terras que eles ocupam, sobrevivendo por meio da caça, pesca, plantio, colheita é indispensável para que eles sobrevivam, desse modo, não se pode permitir que a cultura proprietária moderna e capitalista continue tratando a terra como mercadoria e com isto dificultando e evitando que essas pessoas tenham seus direitos assegurados.

Conclui-se que a cultura proprietária moderna e capitalista não entende a terra do mesmo modo que a indígena, como aduz MARÉS (2015) no artigo "Terra mercadoria, terra vazia: povos, natureza e patrimônio cultural', a terra nessa cultura proprietária moderna e capitalista é mercadoria. Para que a terra seja considerada 
efetiva necessita estar vazia, pois se permanentemente ocupada pelos índios são obstáculos que impedem o exercício do direito de propriedade, o que por consequência prejudica o desenvolvimento capitalista em que o valor da terra como mercadoria consiste nela livre, ou seja, sem "obstáculos" à sua fácil comercialização.

\section{CONCLUSÃO}

Como estudado no presente trabalho no mundo inteiro houve manifestações em prol de alterações nos ordenamentos jurídicos contra o sistema Capitalista para que o entendimento de propriedade não estivesse totalmente desvinculado do outro, ou seja, não fosse somente para fins individualistas capitalistas, no Brasil, os trabalhadores passaram a também pressionar e se manifestar para mudar o país, para reforma agrária que gerou em 1964 a edição do Estatuto da Terra, assim como, os movimentos pela terra como o Movimento dos Trabalhadores Rurais Sem Terra (MST), em 1984, proporcionaram o estabelecimento positivado da "função social da propriedade" na Constituição Federal de 1988, as leis agrárias (como a Lei 8.629/93) e as matérias infraconstitucionais pertinentes a terra.

Há dados oficiais como o senso de 2010 do IBGE (Instituto Brasileiro Geografia e Estatística) em que comprova a existência de cerca 817.963 mil índios, distribuídos entre 220 povos, compondo cerca de $0,4 \%$ da população nacional, onde 82 grupos tribais ainda não haviam sido catalogados pelo órgão de assistência ao índio, o que dificulta tanto o reconhecimento quanto proteção deles pela Fundação Nacional do índio-FUNAI, o que como visto dificulta a legalidade em se garantir os direitos sobre as terras que eles ocupam, sobrevivendo por meio da caça, pesca, plantio, colheita é indispensável para que eles sobrevivam, ressalvando que os estudos da cultura indígena como a dos Xamãs comprovam que o índio não entende a terra da mesma forma que os outros povos, a visualiza no seu caráter sagrado como responsável pela sua identidade, por isso, a necessidade da reserva indígena. 
Para que as reservas indígenas possam receber proteção e garantir o seu uso por meio das práticas dos mesmos, o que seria o uso tradicional das terras que as comunidades podem fazer, pois na atualidade são verificáveis as mudanças de hábitos, costumes, mas eles preservam a identidade como cultura, até mesmo como foi observado durante o presente trabalho, pela forma com a qual a terra é considerada, onde a extração do ouro é compreendida como algo danoso, errado, ruim, pois afeta escalas imensuráveis como o próprio mundo espiritual, mundo que 0 homem branco não consegue compreender para entender a dimensão e a importância de se manter as terras protegida, dessa forma, a observância do termo uso tradicional pela Constituição Federal de 1988 acaba por prejudicar as comunidades indígenas, o que torna essa possibilidade de uso um direito não efetivo, já que ainda permanece a discussão de como podem explorar essas terras, até mesmo defendo alguns que é possível, desde que, indispensável assistência dos órgãos de fiscalização, mas busca-se asseverar que legalmente é direito dos indígenas usar o seu habitat sendo sua faculdade até mesmo exploração que também é a função social da reserva indígena.

\section{REFERÊNCIAS}

ACSERALD, Henri; BARROS, Juliana; PINTO, Raquel Giffoni. Estratégias de controle territorial: confluências autoritárias entre políticas militares e empresariais. Direitos em conflito: movimentos sociais, resistência e casos judicializados. V.2. Org. José Antônio Peres Gediel... [et. al]. Curitiba: Kairós, 2015.

AGNOLIN, Adone. Antropofagia ritual e identidade cultural entre os Tupinambás. Rev. Antropol. vol. 45 n.1. São Paulo, 2002.

ALBERT, Bruce. O ouro canibal e a queda do céu: uma crítica xamânica da economia política da natureza. Brasília: Série Antropologia, 1995.

ALMEIDA, Alfredo Wagner de. "Novos colonialismos": diálogos evanescentes numa fronteira em movimento. Direitos em conflito: movimentos sociais, resistência e casos judicializados. V.2. Org. José Antônio Peres Gediel... [et. al]. Curitiba: Kairós, 2015. 
ASSIS, Luiz Gustavo Bambini de. A evolução do direito de propriedade ao longo dos textos constitucionais. Revista da Faculdade de Direito da Universidade de São Paulo. v. 103 p. 781 - 791 jan./dez. 2008.

ALVES, Manuela Caldas Fontenele; MATIAS, João Luís Nogueira. Historicidade do direito de propriedade no Brasil. História do direito [Recurso eletrônico on-line] organização CONPEDI/UFS; Coordenadores: Gustavo Silveira Siqueira, Antonio Carlos Wolkmer, Zélia Luiza Pierdoná - Florianópolis: CONPEDI, 2015.

CALMON, Daniela Pessoa de Goes; PINTO, David Bachmann. A função social da propriedade e os conflitos sobre a terra ou a função social da terra e os conflitos sobre a propriedade. Artigo classificado em $3^{\circ}$ lugar na XII Jornada. De Iniciação Científica de Direito da UFPR - 2010. Disponível: << http://www.direito.ufpr.br/jornadasic/pdfs/A\%20funcao\%20social\%20da\%20proprieda de $\% 20$ e 20 os $\% 20$ conflitos $\% 20$ sobre\%20a\%20terra\%20ou\%20a\%20funcao\%20soc ial\%20da\%20terra\%20e\%20os\%20conflitos\%20sobre\%20a\%20propriedade.pdf >> Acesso:16 jun. 2018

CHALHUB, Melhim Namen. Função social da propriedade. Revista da EMERJ. v. 6, n. 24, 2003.

CHICANGANA-BAYONA, Yobenj Aucardo. Os Tupis e os Tapuias de Eckhout: O declínio da imagem renascentista do índio. Varia Historia. Belo Horizonte, vol. 24, no 40. p.591-612, jul/dez 2008.

COULANGES, Fustel de. A Cidade Antiga. Tradução Frederico Ozanam Pessoa de Barros. Disponível: $\quad<\quad$ http://bibliotecadigital.puc-campinas.edu.br/services/ebooks/Fustel\%20de\%20Coulanges-1.pdf>> Acesso: 15 jun. 2018

MAGALHÃES, Leandro Henrique. O índio brasileiro no livro didático. Hist. Ensino. Londrina, v. 6, p. 73-89, out. 2000.

MARCHINI, Rodrigo Sérgio Meirelles. A proteção constitucional das terras indígenas brasileiras no período Republicano: Evolução e estagnação. Dissertação de Mestrado para obtenção do título de mestre pelo departamento de Direito Civil. História do Direito. Faculdade de Direito da Universidade de São Paulo, 2011.

OLIVEIRA, Assis da Costa. Sensibilidade jurídica e embate colonial: análise do caso Saramaka Vs. Suriname. Direito e Práxis. V. 4, n.1, 2012. p. 26-53.

PINHO, Leandro Garcia. Jesuítas e pensamento mestiço: adaptação e ocidentalização nos escritos quinhentistas luso-americanos de Anchieta, Soares e Cardim. Universidade Federal de Juiz de Fora Instituto de Ciências Humanas programa de pós-graduação em ciência da religião. Tese apresentada ao 
Programa de Pós-Graduação em Ciência da Religião como requisito parcial à obtenção do título de Doutor. Juiz de Fora, 2006.

PODELESKI, Onete da Silva. Lei de Terras de 1850. Revista Santa Catarina em História de Florioanópolis. v.1, n.2, 2009.

RESENDE, Ana Catarina Zema De. DIREITOS E AUTONOMIA INDÍGENA NO BRASIL (1960 - 2010): uma análise histórica à luz da teoria do sistema-mundo e do pensamento decolonial. Universidade de Brasília - UnB. Instituto de Ciências Humanas. Programa de Pós-Graduação em História. Tese apresentada ao Programa de Pós Graduação em História do Instituto de Ciências Humanas da Universidade de Brasília, 2014.

SALGADO, Juan Manuel; GOMIZ, María Micaela. Convenio 169 de la O.I.T. sobre Pueblos Indígenas: su aplicación en el derecho interno argentino. 2 ed. Argentina: Neuquén.

SANTAMARÍA, Rosembert Ariza. El regime jurídico de las tierras, la convención 169 de la OIT y la actuación del poder judicial frente a los derechos del territorio.

SANTOS JÚNIOR, Valdeci dos. Os índios Tapuias do Rio Grande do Norte antepassados esquecidos. Universidade do Rio Grande do Norte. Grupo de Pesquisa: História da Região Oeste do Rio Grande do Norte. Mossoró, 2006.

SILVA, José Afonso da. Parecer sobre o marco temporal de 88. Disponível: http://www.mpf.mp.br/atuacao-tematica/ccr6/documentos-epublicacoes/artigos/docs_artigos/jose-afonso-da-silva-parecer-maio-2016-1.pdf. Acesso: 13 dez. 2017.

SOUZA FILHO, Carlos Frederico Marés de. A constitucionalidade do direito quilombola. Estratégias de controle territorial: confluências autoritárias entre políticas militares e empresariais. Direitos em conflito: movimentos sociais, resistência e casos judicializados. V.1. Org. José Antônio Peres Gediel... [et. al]. Curitiba: Kairós, 2015.

Terra mercadoria, terra vazia: povos, natureza e patrimônio cultural. Revista Insurgência. Ano 1. V. 1. N. 1 jan/jun., 2015. p. 57-71. 